\title{
When does conservation genetics matter?
}

\author{
WILLIAM AMOS* \& ANDREW BALMFORD \\ Department of Zoology, University of Cambridge, Downing Street, Cambridge CB2 3EJ, U.K.
}

Is this short review we explore the genetic threats facing declining populations, focusing in particular on empirical studies and the emerging questions they raise. At face value, the two primary threats are slow erosion of genetic variability by drift and short-term lowering of fitness owing to inbreeding depression, of which the latter appears the more potent force. However, the picture is not this simple. Populations that have passed through a severe bottleneck can show a markedly reduced ability to respond to change, particularly in the face of novel challenges. At the same time, several recent studies reveal subtle ways in which species are able to retain more useful genetic variability than they 'should', for example by enhanced reproductive success among the most outbred individuals in a population. Such findings call into question the validity of simple models based on random mating, and emphasize the need for more empirical data aimed at elucidating precisely what happens in natural populations.

Keywords: endangered species, evolutionary potential, genetic diversity, heterozygosity, inbreeding depression, population management
The perceived importance of genetic problems in the conservation of endangered species has fluctuated considerably over the last two decades, and remains the subject of debate. An early high-profile case study reported that cheetahs have low levels of genetic variability, poor sperm quality and poor reproductive success in captivity (O'Brien et al., 1983; O'Brien et al., 1985; O'Brien et al., 1986). It was concluded that the species had suffered a genetic bottleneck, stripping it of variability and leaving it prone to problems associated with inbreeding depression. Although later studies (Caro \& Laurenson, 1994; Caughley, 1994; Merola, 1994; Caro, 2000) have revealed many inconsistencies and the story has now been largely rewritten, the cheetah project helped stimulate growing interest in the role of genetics in conservation.

Today, many conservation studies include a genetic element, and the list of possible problems being considered has expanded to embrace loss of evolutionary potential, susceptibility to disease, mutational meltdown, and more. In this review we re-examine the main genetic threats faced by small and declining populations and discuss the empirical basis for deciding which of these are most likely to pose serious problems over the sorts of time-scales that concern conservation practitioners. In doing so, we have made a conscious effort to look to the future by speculating about areas and concepts which are only now coming to light.

Of the various possible genetic problems which face a declining population, loss of genetic variability and inbreeding depression have historically received most attention (O'Brien, 1994). Although often treated as one and the same phenomenon, these two processes are in reality very different, and operate over radically different timescales. In general, variability is lost very slowly, usually over hundreds

*Correspondence. E-mail: w.amos@zoo.cam.ac.uk or thousands of generations. Rate of loss is inversely proportional to the genetic effective population size $\left(N_{\mathrm{e}}\right)$. In practice, this means that the primary determinants of loss are the size of the lowest population to date, and the time (in generations) for which it has been held at around that level. In contrast to loss of variability, the effects of inbreeding depression will begin to be felt within a few generations of a decline, and their strength will depend primarily on the magnitude of the drop in population size. This point is illustrated by considering a large population reduced to an $N_{\mathrm{e}}$ of just 20. After five generations at this size, essentially all surviving individuals will be close relatives and, depending on the breeding system, inbreeding depression would likely be at or near its most severe. In contrast, according to the wellknown equation

$H_{t}=H_{0}\left(\begin{array}{ll}1 & 1 / 2 N_{\mathrm{e}}\end{array}\right)^{t}$

where $H_{0}$ is initial heterozygosity and $H_{\mathrm{t}}$ is heterozygosity $t$ generations after a decline to size $N_{\mathrm{e}}$ (James, 1970), on average some $88 \%$ of heterozygosity at selectively neutral loci will remain.

\section{Loss of variability}

When a population is driven to the brink of extinction and held there for several generations, a large proportion of that species' neutral variability may be eroded by chance loss of alleles. One well-documented case of such genetic drift comes from the Mauritius kestrel, which was reduced to a single pair in the 1950s, recovered slowly at first, but now numbers over 500 birds. Comparisons of microsatellite diversity before and after this bottleneck reveal that some $50 \%$ of the heterozygosity present in 19th century specimens has been lost, in good 
agreement with theoretical expectations based on the length and depth of the bottleneck (Groombridge et al., 2000).

Fortunately, the Mauritius kestrel looks to be the exception not the rule. Using the above equation, it is easy to show that loss of heterozygosity is extremely slow compared with the timescales over which conservation biology operates. For example, a mammal with generation length of 10 years reduced to an $N_{\mathrm{e}}$ or 50 in 1900 would still have $90 \%$ of its heterozygosity today. Species with shorter generation lengths would experience greater loss per year for a given population size, but such species generally exist at higher population densities with larger effective population sizes even when in decline. This expectation is borne out by a recent study in which expected losses of heterozygosity were calculated for 80 declining mammal populations, including most of the 'classic' examples of genetic depletion (Menchini et al. submitted). The results are striking. Over $90 \%$ of all species are unlikely to have lost more than $10 \%$ of their heterozygosity (see Fig. 1).

Thus, while many studies claim to show a link between known population bottlenecks and low levels of genetic variability (Hoelzel et al., 1993; O’Brien, 1994), closer examination usually reveals that the expected loss of heterozygosity is far less than might be thought (Amos \& Harwood, 1998). For example, claims that the cheetah has lost ' $90-99 \%$ ' of its variability through 'one or more bottlenecks' (O'Brien, 1994) are difficult to reconcile with a current population size numbering thousands (Amos \& Harwood, 1998). Indeed, to lose $99 \%$ of its variability would require 16 generations of sib-sib mating $\left(N_{\mathrm{e}}=2\right)$ ! Similarly, the northern elephant seal is described as extremely genetically depleted (Hoelzel et al., 1993), yet excellent historical records show that its bottleneck, although severe, probably only lasted two or three generations. Based on plausible parameter values, it seems highly unlikely that this decline could explain the loss of more than $25 \%$ of the species' nuclear genetic variability, although mitochondrial variability may have been affected more strongly (Weber et al.,

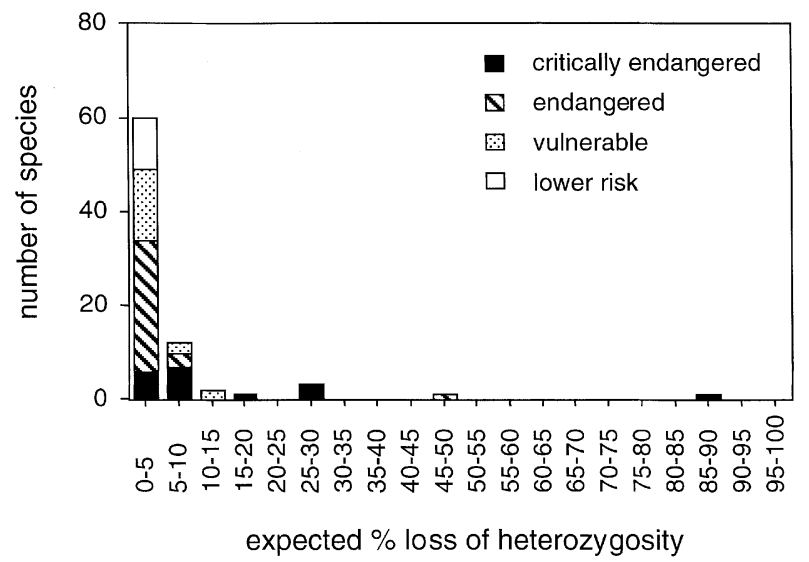

Fig. 1 Frequency distribution of the expected loss of genetic variability for 80 declining mammal populations, in relation to their conservation status (based on Hilton-Taylor, 2000). Loss of heterozygosity was estimated assuming the population declined instantaneously to its lowest recorded size, and has remained there since. From Menchini et al., submitted.
2000). Consequently, other factors must be responsible for the species' current low nuclear variability. The possibility that extreme but short-term depletion may have little impact on a species' heterozygosity is supported by data from the Antarctic fur seal. This species suffered parallel and maybe more severe depletion at the hands of sealers (Bonner, 1968), yet currently shows little evidence of genetic erosion (Wynen et al., 2000; Gemmell et al., 2001). Results like these run counter to intuition because moderate heterozygosity persisting in bottlenecked populations may have been poorly reported (Amos \& Harwood, 1998).

Two other points about heterozygosity are worth considering. The first is that cheetahs and northern elephant seals are only two of many species which show very low variability for no clear reason. Several species have low heterozygosity despite no evidence of population decline, and carnivores in particular appear to have low variability relative to other mammals (Merola, 1994). One example is the European badger, whose lack of variability for years frustrated biologists keen to use genetic markers to study its breeding behaviour and population structure (accordingly this fact has not been published because it is a negative result!). Clearly, one should be cautious in inferring that low heterozygosity in any species, threatened or otherwise, is necessarily the result of bottlenecking (Amos \& Harwood, 1998).

The second point concerns the relationship between the variability being measured and the variability that is important to the organism. Heterozygosity is only one measure of genetic diversity, and tends to be less sensitive to population bottlenecks than alternatives such as allelic diversity. More importantly, genetic diversity is usually assayed by (presumed) neutral markers. These reflect the passive loss of variability through genetic drift but are less informative about variability that impinges on fitness. For example, a strongly balanced polymorphism like sickle cell anaemia in humans would be almost impossible to eliminate by bottlenecks alone. Consequently, loss of immediately useful variability will always tend to lag behind loss of neutral variability. Moreover, selection during population declines may favour heterozygosity itself through overdominance or genetic incompatibility (Tregenza \& Wedell, 2000). For example during population crashes of Soay sheep, individuals that are heterozygous for adenosine deaminase show higher survival than homozygotes (Gulland et al., 1993), and it is noted that population collapses can actually trigger an increase in mean heterozygosity of the population as a whole (Bancroft et al., 1995; Pemberton et al., 1996).

\section{The consequences of loss of variability}

Nevertheless, assuming that a species has lost useful variability, what are the likely consequences? One possibility is that fitness will be reduced as a direct consequence of a reduction in the number of heterozygous loci. This proposition stems from the fact that some, and maybe much, selectively important variability is maintained by balanced polymorphisms in which the heterozygote is fitter than either homozygote. Although such locus-specific effects could operate entirely separately from the more general aspects of inbreeding depression, in 
practice the two processes are virtually impossible to disentangle.

Perhaps the main consequence of reduced variability is thought to lie in lowering a population's ability to react to novel challenges. Once again there is a huge discrepancy between the plausible and widespread assumption that adaptability is compromised and the handful of empirical studies that provide direct evidence. Logically, the more important the genetic variability, both in terms of absolute selective value and the proportion of time any advantage is manifest (some variability may be neutral except under exceptional circumstances), the more likely it would be to be retained. Hence, drift tends preferentially to remove the variability which is currently least important to the organism. This argument probably holds for challenges already being met by the organism, but may be less relevant for reaction to novelty. For example, Drosophila does not normally encounter high salinity, and when four populations of variously inbred and outbred flies were exposed to increasing levels of salt $(\mathrm{NaCl})$, the relatively outbred populations proved better able to adapt over time (Frankham et al., 1999; see Fig. 2).

While this salinity challenge experiment provides support for a link between heterozygosity and evolutionary potential within a species, the relationship across species is less clear. Most obviously, the extreme polymorphism shown by mammalian MHC genes is thought to be crucial for defence against disease, but evidence from cross-species comparisons is ambiguous. On the one hand, Northern elephant seals show very low MHC diversity yet appear much less prone to a range of disease than Californian sealions which swim in the same waters and have not been bottlenecked (F. Gulland, pers. comm.). On the other hand, European harbour seals have very low diversity and suffered very high mortality from Phocine Distemper Virus (PDV), which is endemic and less virulent in several arctic species. Whether the high mortality and rapid spread of PDV among harbour seals resulted from novel exposure, low MHC diversity or some combination is still unclear, and illustrates the problems inherent in trying to interpret these complex and long-term causalities. Interestingly, pathogens may not be the only factor maintaining high MHC diversity. Several vertebrates use MHC cues to detect, and in some cases avoid mating with, relatives. Such behaviours will tend to enhance MHC diversity regardless of any selective effects owing to disease.

\section{Inbreeding depression}

At every generation, a species' genome suffers many new mutations, the majority of which are detrimental because there are many more ways to disrupt gene function than there are to improve it. In order to prevent genomic degeneration, these deleterious mutations must be removed as fast as they arise, through differential mortality/fecundity. Because most genes in diploid organisms can operate satisfactorily with only a single copy, loss of function mutations are generally recessive, showing their effect only in the homozygous state. Consequently, loss of fitness occurs when homozygosity is increased, usually through matings between close relatives. This phe-
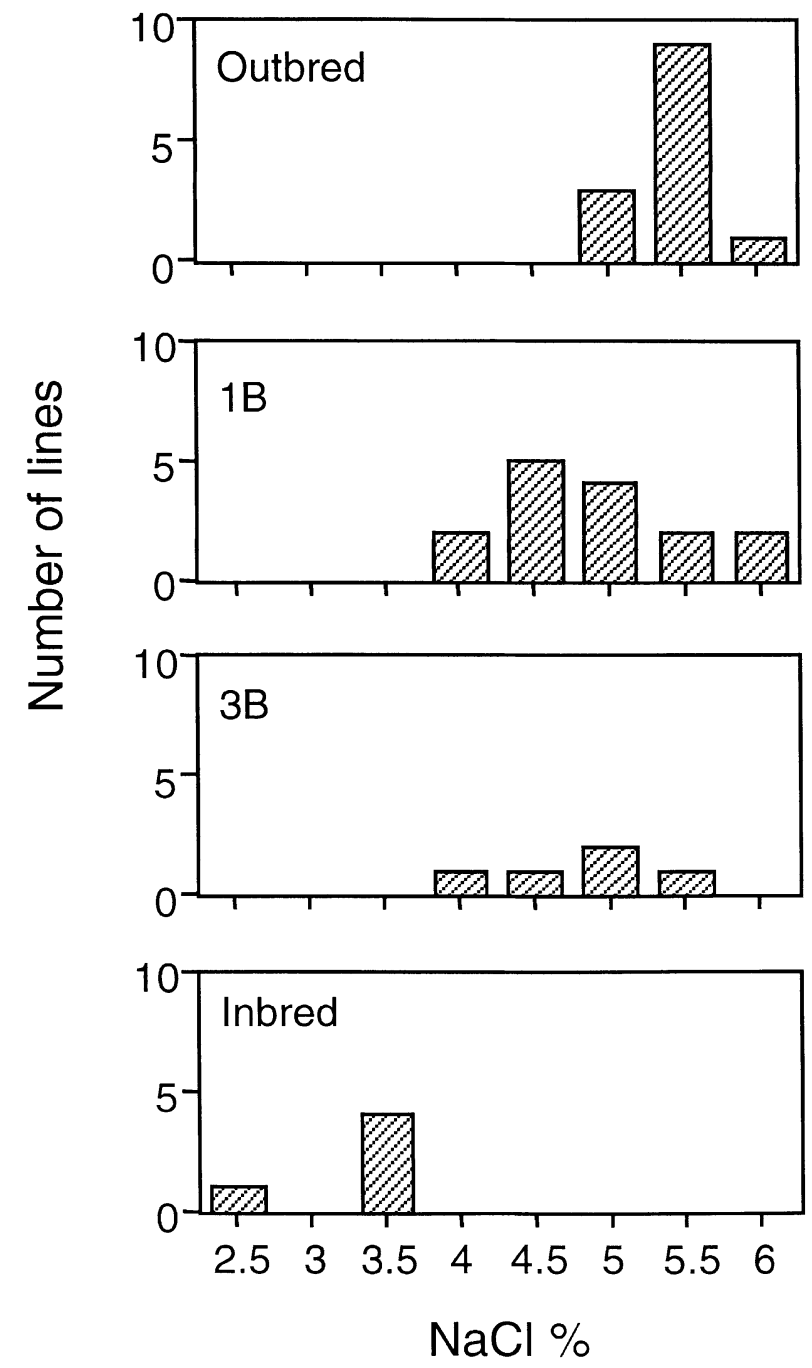

Fig. 2 The ability of fruit flies to tolerate increasing $\mathrm{NaCl}$ concentrations, as a function of whether they are outbred (top), have been bottlenecked at one pair for one or three generations (1B, 3B), or have been highly inbred (bottom). The plot shows the $\mathrm{NaCl}$ concentrations at which populations became extinct. Redrawn from Frankham et al. (1999).

nomenon is known as inbreeding depression, and it can affect a population almost immediately following decline due to the overall increase in relatedness between individuals. The effect is transient because the reduced fitness of relatively inbred individuals purges the genetic load, the its strength is proportional to the magnitude of the decline.

The consequences of inbreeding depression have been widely reported and include reduced fecundity among pairs of close relatives and reduced survival of inbred individuals (Ralls et al., 1970; Saccheri et al., 1996; Newman \& Pilson, 1997; Keller, 1998; Crnokrak \& Roff, 1999; see Hedrick \& Kalinowski, 2000 for a recent review). For example, when the butterfly Bicyclus anynana is forced through a bottleneck of one pair, fecundity drops to $\approx 20 \%$, but often returns to normal 
levels within a few generations of sustained inbreeding, presumably as a result of the purging of deleterious alleles (Saccheri et al., 1996); see Fig. 3, and below). Parallel experiments based on bottlenecks of five pairs show a much reduced fecundity drop, and when 10 pairs are used, no detectable drop is present (Saccheri et al., 1996).

However, the picture is not straightforward. It is increasingly evident that environmental stress such as food and water shortage can uncover effects not seen under less demanding conditions. Convincing studies have been carried out in the laboratory, for example using the flower ragged robin (Hauser \& Loeschke, 1996) and Drosophila (Dahlgaard \& Hoffmann, 2000). Field evidence for inbreeding depression and its interaction with stress comes from experimental work on white-footed mice (Jimenez et al., 1994). When wild-caught mice are subject to full-sib mating in captivity for three of four generations, and then returned to the capture site, they show greater mass loss and lower survivorship than the progeny of outbred matings. When equivalent mice are retained in the laboratory, inbreeding depression is much less severe.

There is now also growing evidence that inbreeding depression can impact not just individuals but entire populations. For instance, the Mandarte Island song sparrow persists close to the edge of viability at a peak size of some 200 birds (Keller et al., 1994; Keller, 1998). Occasional hard winters result in population crashes in which only a handful of birds survive. Pedigree analysis shows that relatively inbred individuals are more likely to die in crashes than those whose parents were less related. A similar effect is seen on a larger scale in Glanville fritillary butterflies in Finland, where many, widely dispersed and sometimes very small patches of food plant provide

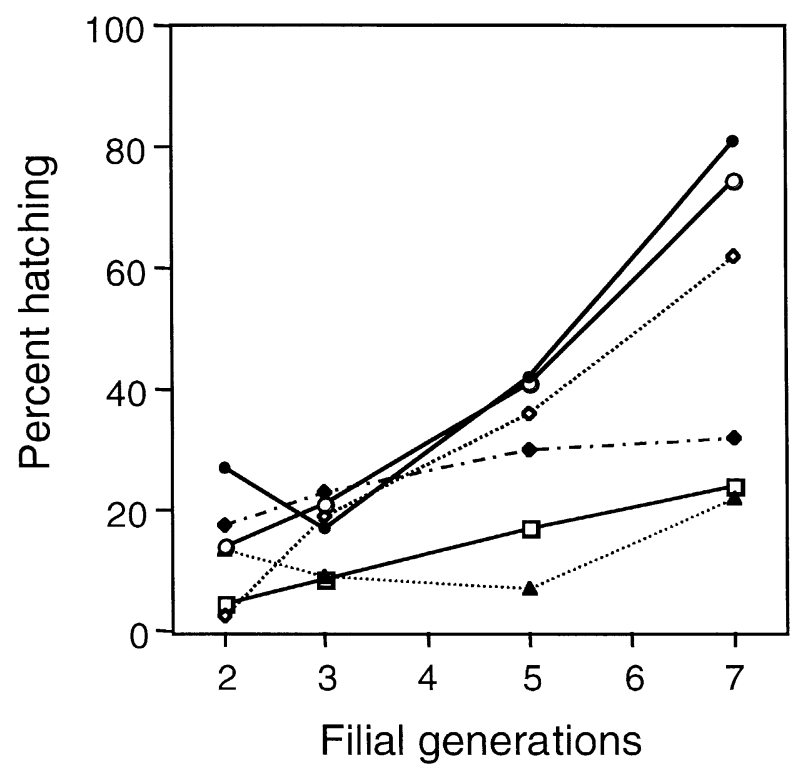

Fig. 3 Hatching success of six one-pair lines of Bicyclus anynana, compared with that of outbred control lines. All lines show some recovery from initial inbreeding depression, and three lines show a marked recovery. Redrawn from Saccheri et al., 1996. breeding sites for small populations, many of which persist for only one or a few seasons (Saccheri et al., 1998). Here, inbred populations have a higher extinction probability than outbred populations. Although it is early to generalize, these studies suggest that the most important effect of inbreeding depression lies with its tendency to exacerbate the consequences of environmental downturns.

Until recently, inbreeding effects were studied almost exclusively in families born to close relatives, either opportunistically as in the Mandarte Island sparrows, or experimentally, as in many insect, plant and mouse studies. This is partly because any effects will be stronger and hence more detectable in extreme cases and partly because of the difficulties of quantifying the level of inbreeding where the relatedness of parents is too distant to be determined by pedigrees. An unwitting consequence is the perception that inbreeding effects occur almost exclusively in 'incestuous' families where the parents share very recent common ancestry. However, new techniques now allow any level of inbreeding to be determined with ease and without the need for pedigrees. Essentially more sophisticated variants of crude heterozygosity, these measures assess parental similarity via the similarity of paternally and maternally inherited alleles. For example, the squared difference in length between microsatellite alleles provides a measure that is expected to scale linearly with time since common ancestor. Calculated between alleles at a locus and then averaged over many loci, the resulting statistic, named mean $d^{2}$, reflects the overall genomic similarity of an individual's parents (Coulson et al., 1998).

Using mean $d^{2}$ and related measures such as standardized heterozygosity (Coltman et al., 1999), a measure of average heterozygosity which allows for differences in variability among loci, the consequences of parental similarity are now being extended greatly to embrace all individuals, not just 'incestuous' families. In deer and seals, mean $d^{2}$ predicts juvenile survival, the progeny of genetically dissimilar parents being heavier and surviving better (Coltman et al., 1998; Coulson et al., 1998). In sheep, standardized heterozygosity explains significant variation in parasitic worm burdens, which in turn influence survival (Coltman et al., 1999). Subtle effects can even be detected in humans. Using data from a whole genome screen for genetic factors conferring susceptibility to tuberculosis, disease incidence was associated with low mean $d$-squared values on chromosome 15 , coincident with a region identified by traditional linkage mapping as contributing to disease susceptibility (Bellamy et al., 2000). Just as with the sheep, the probability of infection appears to be increased by recessive factors.

Parental similarity can also modulate adult reproductive success. Inbred mice released into seminatural populations show lower success compared with outbred controls (Meagher et al., 2000), and molecular measures of parental dissimilarity correlate positively with reproductive success in a range of vertebrates including deer (Slate et al., 2000) and seals, albatrosses and pilot whales (Amos et al., in press). If these findings prove to be the rule rather than the exception, there are important consequences for mating behaviour and for the maintenance of genetic diversity. 
In most systems, sexual selection favours choice for highquality partners who have inherited desirable qualities from their parents. This reduces variability because reproduction is skewed towards a small number of dominant lineages. In contrast, selection for dissimilar parental combinations increases variability. Which of these opposing forces will 'win' will undoubtedly vary from species to species, but early results indicate that preference for parental dissimilarity may be widespread. Thus, male guppies both recognize and prefer unfamiliar females (Kelley et al., 1999), while in grey seals, females who mate with different males in different seasons give birth to pups who are less paternally related to one another than expected by chance, suggesting females prefer diverse mates (Amos et al., 2001). Preferences of this nature will tend to preserve variability and may provide small and declining populations with an unexpected extra resilience against both inbreeding depression and genetic erosion.

\section{Addressing inbreeding depression in species conservation}

Inbreeding depression can potentially contribute to a so-called extinction vortex (Lacy \& Lindenmayer, 1995), in which decline reduces fitness which in turn hastens the decline, increasing both inbreeding depression and vulnerability to stochastic events in a destructive feedback loop. Two strategies that have been proposed to counteract this phenomenon raise a number of complicated and unsolved issues.

One idea is to adopt a short-term policy of forced inbreeding in order to expose deleterious recessive alleles and thereby purge them from the population. Some species that have been through documented bottlenecks have subsequently shown dramatic recoveries. Examples include the northern elephant seal, Antarctic fur seals, the southern right whale, the southern white rhino and the Mauritius kestrel. These striking rebounds could be explained by a reduction in intraspecific competition, or by the loss of coadapted parasites and diseases. However, strong purging during the nadir of each species' bottleneck could also have increased fitness by decreasing the genetic load. More direct evidence of purging comes from experiments like that on Bicyclus (in Fig. 3), where fecundity in highly inbred lines can recover to normal levels after only a few generations, despite continued inbreeding (Saccheri et al., 1996).

However, in the Bicyclus example, recovery is not guaranteed, and around half the lines show little rebound. Supporting this observation, Hedrick (1994) provides models showing how the consequences of full-sib mating may depend on the genetic basis of inbreeding depression. Where this is the consequence of lethals, purging can occur without substantially increasing extinction, but when inbreeding depression is the result of many detrimental alleles each of small effect, forced inbreeding can cause fixation rather than purging, leading to a reduction in overall fitness. Recent experimental work on flies suggests that not only is the expression of inbreeding depression itself stress-dependent, but also that the relationship between population history and purging may be complex. First, Dahlgaard \& Hoffmann (2000) showed that flies that had been purged under one environmental challenge, retained enhanced susceptibility to unrelated challenges, suggesting that purging may not be general, but instead may involve a (small?) subset of all genes which contribute to inbreeding depression. In a second series of experiment, Reed \& Bryant (2000) studied how inbreeding depression varied over time for populations of different sizes, including one where a population was forced through an effective population size of 5 for one generation ('founder flush'). Their results show that, although some recovery is seen in the founder flush populations, in general, the inbreeding effects persist for at least 24 generations, rather longer than implied by the Bicyclus experiments. Finally, and perhaps most significantly, thorough reviews covering 25 populations of mammals (Ballou, 1997) and 53 plant studies (Byers \& Waller, 1999) conclude that purging reduces inbreeding depression only in some traits, only in some populations, and even then, only to a rather limited extent (Fig. 4).

An alternative answer to the problem of inbreeding depression is based on introduction of new genetic diversity from other populations. In the Mandarte Island sparrow study it was noted that, following each crash, genetic diversity was considerably reduced, but that levels rapidly recovered as the population expanded again (Keller et al., 1994; Keller, 1998). Because regeneration of variability by mutation would take vastly more time, the explanation lay with the one or two immigrants that enter the population each year. These new individuals bring in new diversity and, for the first generation or so, would enjoy excellent reproductive success by dint of their being unrelated to any members of the remnant population they joined. Likewise, deliberate introduction of individuals from elsewhere has been proposed as a management strategy for several isolated and extremely small populations thought to be suffering inbreeding depression (e.g. (Hedrick, 1995; Hedrick et al., 1997), and, in the case of the Mexican wolf, has already been carried out (Kalinowski et al., 1999).

Nevertheless, this approach raises several potential problems (Lynch, 1996). Of general concern is the question of hybridization. There is a fine dividing line between on the one hand the contamination of indigenous gene pools by introduced or escaped exotic species, a problem which many hold to be a major threat (Crivelli, 1995; Levin et al., 1996; Rhymer \& Simberloff, 1996; Huxel, 1999), and, on the other, the deliberate augmentation of an endangered population using a genetically distinct lineage from elsewhere. Is it vital to preserve only biodiversity in its current state (naïvely considered by some to be pristine), or can we assume that natural selection will successfully preserve locally important adaptations while at the same time assimilating the best of what has been introduced (Rhymer \& Simberloff, 1996; see Patten, 2000 for a recent case study)? The jury is still out.

More pragmatically, augmentation of a very small population with individuals from other, larger populations may also refresh the local pool of detrimental recessives. These new recessives would increase in frequency in parallel with the success enjoyed by their bearers. If the receiving population has already survived a severe bottleneck, it may have been purged of many of the strongest factors contributing to its genetic load. Consequently, the introduction of new detrimental 


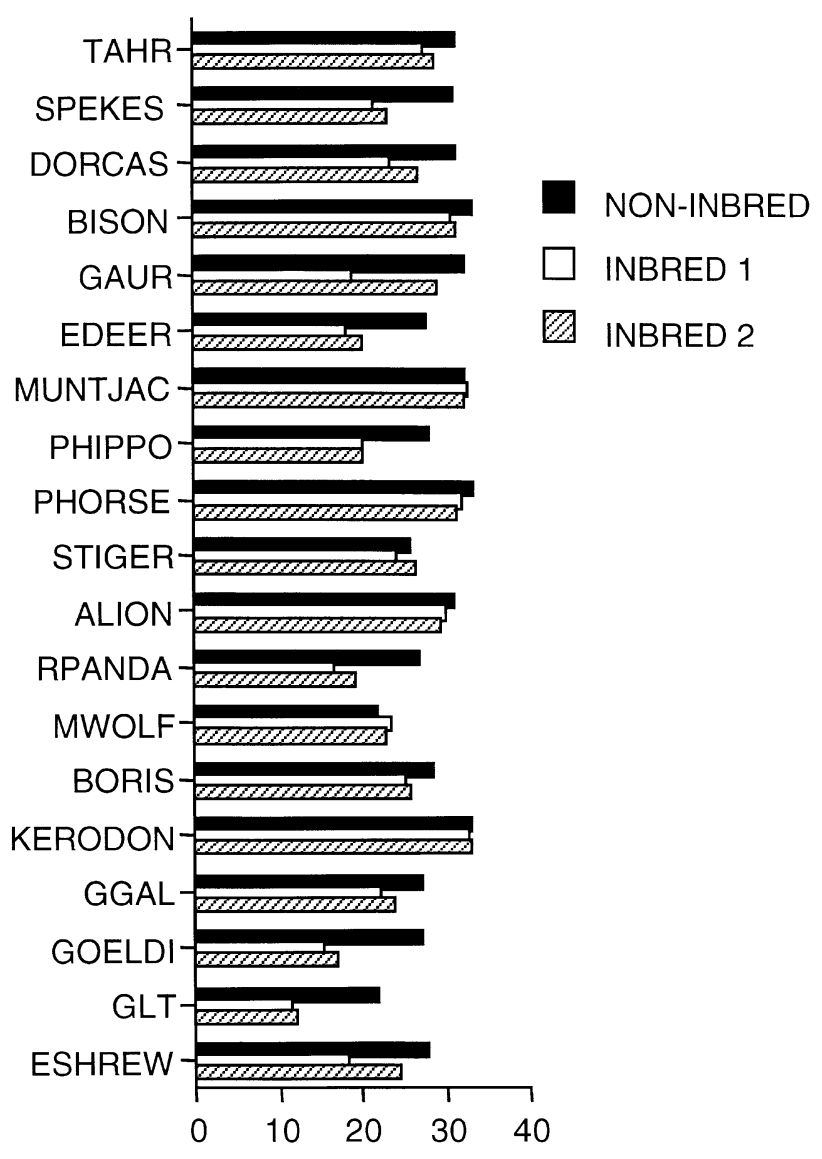

Relative neonatal survival

Fig. 4 Captive neonatal survival in 19 mammal species for noninbred animals, inbred animals (inbred 1), and inbred animals with inbred ancestors (inbred 2). There is significant inbreeding depression in seven species (with asterisks indicating $* P<0.05, * * P<0.001, * * * P<0.001)$. Although 15 species show a trend towards higher survival for inbred animals with inbred ancestors than for other inbred animals, this purging effect is significant only for Sumatran tigers. Redrawn from Ballou, 1997. ESHREW, elephant shrew; GLT, golden lion tamarin $(* * *)$; GOELDI, Goeldi's marmoset $(* * *)$; GGAL, greater galago; KERODON, kerodon; BORIS, boris; MWOLF, Mexican wolf; RPANDA, red panda; ALION, Asiatic lion; STIGER, Sumatran tiger; PHORSE, Przewalski's horse; PHIPPO, pygmy hippopotamus (***); MUNTJAC, muntjac; EDEER, Eld's deer (***); GAUR, gaur; BISON, European bison $(* *)$; DORCAS, Dorcas gazelle $(*)$; SPEKES, Speke's gazelle (***); THAN, nilgri tahr.

alleles could increase its vulnerability to any future bottleneck. In the case of the Mandarte sparrows, it is intriguing to speculate that the repeated population crashes are actually facilitated by incoming 'new blood'. Hence, although genetic augmentation may result in a short-term increase in fitness, this may be followed by a subsequent decline.
Regardless of whether introduced individuals bring with them intrinsically deleterious mutations, i.e. those which will cause loss of fitness in any genetic background, there is also the potential problem of outbreeding depression (Lynch, 1996). Natural selection will tend to create populations that are adapted to the local conditions. Augmentation introduces genetic material that is adapted to a different set of conditions. In some cases, the result is disastrous. For example, when a population of Tatra mountain ibex in Czechoslovakia was 'enriched' by new animals from Sinai and Turkey, the offspring inherited an inappropriate calving date, giving birth in midwinter and losing their progeny (Greig, 1979). Other similar threats include the breaking up of coadapted gene complexes and the introduction of new diseases to which local populations may lack resistance. It seems likely that most augmentation exercises will, at some level, involve risks of this kind. The question is, whether the benefits brought by reduced inbreeding and an increase in numbers will outweigh the tangible threats of outbreeding depression and the need to purge any new deleterious recessives carried by the new blood. As yet, there are no firm rules.

One important issue may be the size of the two populations under consideration. Where the donor population has itself been small for some time (as in the case of all Mexican wolf lineages; see Hedrick et al., 1997), it may carry a low genetic load, and hence the risk of its individuals introducing deleterious alleles into the recipient population may be slight. However, where the donor population is large, it is less likely to have been purged of its genetic load, and hence direct introduction of its members into a far smaller population may be ill-advised. One way around this could be deliberate inbreeding of individuals from the large donor population, to purge them of deleterious alleles prior to any introduction, though this may not be a cost-effective approach to saving a small population of a species which is more abundant elsewhere.

\section{Mutational meltdown}

One final genetic problem which may threaten small populations is mutational meltdown (Lynch, 1993). The idea is that deleterious mutations need to be removed by natural selection, and this usually invokes differential mortality among individuals carrying greater or lesser genetic loads. If a population starts declining, the number of individuals available to get rid of deleterious mutations by selective death dwindles, purging becomes less and less efficient, the load will build up and the average fitness of the population will fall. The result could be a form of destructive feedback loop similar to the extinction vortex. Theoretical studies suggest the process will be most important in small asexual populations (Lynch, 1993) although it cannot be ruled out even in large sexual populations (Bernardes, 1995).

Despite the theoretical precedent, an experimental analysis of genetic load in fruit flies - assessed as the difference in fitness between individuals removed from a population and inbred, or removed and not inbred - reveals that even after 45 generations, load does not differ between populations with $N_{\mathrm{e}}=25$, and populations with $N_{\mathrm{e}}$ set to 500 (Fig. 5; see 


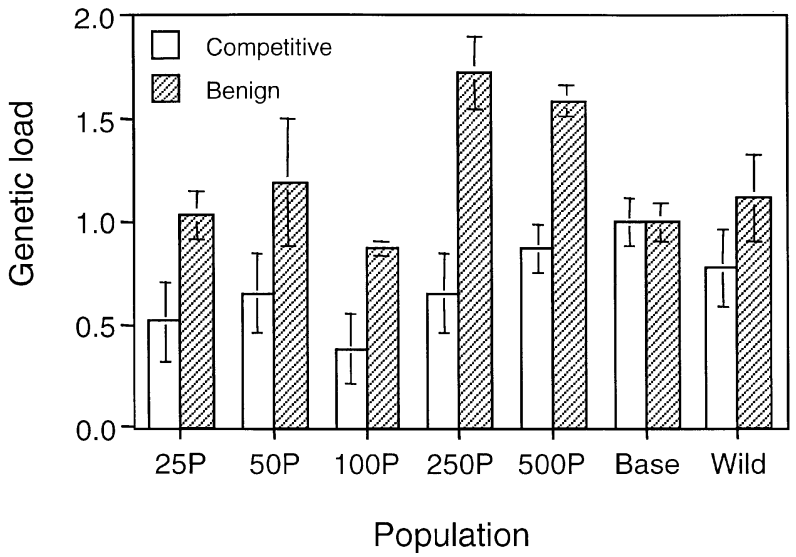

Fig. 5 The genetic load of fruitfly populations maintained for 45 generations at $N_{\mathrm{e}} \mathrm{s}$ of 25, 50, 100, 250 and 500, and of base and wild control populations. Genetic load is assessed as the difference in fitness of noninbred and inbred lines, measured under competitive and benign conditions, and expressed as load relative to the base population. Bars give means and standard errors. (Redrawn from Gilligan et al., 1997.)

Gilligan et al., 1997). These results suggest that, even though mutational meltdown may pose a problem for populations held at low levels for very long periods of times, it is unlikely to affect small populations over the $\sim 100$-year timescales considered by most conservation planners. The reason for this discrepancy between theoretical predictions and experimental systems is unclear. Drosophila may be the exception rather than the rule. Perhaps more likely is the possibility that cryptic mate choice, sperm competition, differential reproductive rates among adults or other mechanisms contribute to ameliorate if not eliminate this theoretical possibility (Jennions \& Petrie, 2000; Tregenza \& Wedell, 2000).

\section{The wider importance of genetics}

In this review we have concentrated entirely on the direct genetic consequences of population decline, and the role of genetic diversity in the survival of endangered populations. We have purposefully put to one side the subject of how genetics can be used as a tool to elucidate problems and to guide management decisions. This includes exciting developments such as new ways to reconstruct population histories, methods for identification of significant units for conservation, forensic tracking of individuals, policing of illegal trade, and the basic science of understanding breeding behaviour and population structure (Avise, 1996).

\section{Conclusions}

Of the two most important problems genetic threats facing declining populations, inbreeding depression seems the most likely, at face value, to exacerbate decline and hasten extinction, particularly where the reduction in population size has been very great and under conditions which are stressful rather than benign. In contrast, loss of neutral variability occurs very slowly and 'useful' variability is likely to be lost more slowly still. Recent studies have 'muddied the waters' by showing that inbreeding effects are not restricted to reduced fecundity in matings between close relatives. Instead, dissimilar pairs may produce fitter than average offspring, and breeding behaviour often seems to have evolved to exploit this fact. Such patterns could have a profound influence on the genetic dynamics of threatened populations, and suggest that theoretical models based entirely on random mating need to be revisited. At the same time, the importance of diversity in resisting pathogens is becoming more apparent, and the first studies measuring evolutionary potential have shown that it is reduced in inbred lines of fruit flies. The key question is whether these trends reflect what actually happens in nature, or whether most species have evolved suites of behaviours that negate the worst aspects of inbreeding depression and allow unexpectedly efficient retention of useful variability. With many highly detailed studies in the pipeline, we are optimistic that answers will soon emerge, and that the current patchwork of oftencontradictory observations can be woven into a more unified explanatory framework. The more complete this becomes, the more effective management strategies will be at countering genetic threats constructively and with minimal risk.

\section{Acknowledgements}

We are very grateful to Tim Caro and one anonymous reviewer for perceptive comments that helped to improve this manuscript considerably.

\section{References}

AMOS, W. AND HARWOOD, J. 1998. Factors affecting levels of genetic diversity in natural populations. Phil. Trans. R. Soc. B, 353, 177-186.

Amos, w., worthington wilmer, J. AND Kokкo, H. 2001. Do female grey seals select genetically diverse mates? Anim. Behav., 62, 157-164.

AVISE, J. C. 1996. The scope of conservation genetics. In: Avise, J. C. and Hamrick, J. L. (eds) Conservation Genetics. Case Histories from Nature, pp. 1-9. Chapman \& Hall, New York.

BALLOU, J. 1997. Ancestral inbreeding only minimally affects inbreeding depression in mammalian populations. J. Hered., 88, 169-178.

BANCROFT, D. R., PEMBERTON, J. M., ALBON, S. D., ROBERTSON, A., MACCOLL, A. D. C., SMITH, J. A. ET AL. 1995. Molecular genetic variation and individual survival during population crashes of an unmanaged ungulate population. Phil. Trans. R. Soc. B, 347, 263-273.

Bellamy, R., BeYers, N., McADAM, K. P. W. J., RUWENDE, C., GIE, R., SAMAAI, P. $E T A L$. 2000. Genetic susceptibility to tuberculosis in Africans: a genome-wide scan. Proc. Natl. Acad. Sci. U.S.A., 97, 8005-8009.

BERNARDES, A. T. 1995. Mutational meltdown in large sexual populations. J. Physique, 5, 1501-1515.

BOnNer, w. N. 1968. The fur seal of South Georgia. Br. Ant. Surv. Sci. Rep., 56, 1-81.

BYERS, D. L. AND WALLER, D. M. 1999. Do plant populations purge their genetic load? Effects of population size and mating history on inbreeding depression. Ann. Rev. Ecol. Syst., 30, 479-513.

CARO, T. M. AND LAURENSON, M. K. 1994. Ecological and genetic factors in conservation: a cautionary tale. Science, 263, 485-486.

CARo, T. 2000. Conservation over behaviour and genetics in cheetah conservation. In: Gosling, L. M. and Sutherland, W. J. (eds) 
Behaviour and Conservation. Cambridge University Press, Cambridge.

CAughley, G. 1994. Directions in conservation biology. J. Anim. Ecol., 63, 215-244.

COLTMAN, D. W., BOWEN, W. D. AND WRIGHT, J. M. 1998. Birth weight and neonatal survival of harbour seal pups are positively correlated with genetic variation measured by microsatellites. Proc. R. Soc. B, 265, 803-809.

Coltman, D. W., Pilkington, J. G., SMith, J. A. AND PEMBerton, J. M. 1999. Parasite-mediated selection against inbred Soay sheep in a free-living island population. Evolution, 53, 1259-1267.

COUlson, T. N., PEMBerton, J. M., Albon, S. D., BeAumont, M., MARSHALL, T. C., SLATE, J. ET AL. 1998. Microsatellites reveal heterosis in red deer. Proc. R. Soc. B, 265, 489-495.

CRIVELLI, A. J. 1995. Are fish introductions a threat to endemic freshwater fishes in the northern Mediterranean region? Biol. Cons., 72, 311-319.

CRNOKRAK, P. AND ROFF, D. A. 1999. Inbreeding depression in the wild. Heredity, 83, 260-270.

DAHLGAARD, J. AND HOFFMANN, A. A. 2000. Stress resistance and environmental dependency of inbreeding depression in Drosophila melanogaster. Conserv. Biol., 14, 1187-1192.

FRANKHAM, R., LEES, K., MONTGOMERY, M. E., ENGLAND, P. R., LOWE, E. H. AND BRISCOE, D. A. 1999. Do population size bottlenecks reduce evolutionary potential? Anim. Cons., 2, 255-260.

GEMMELL, N. J., BURG, T. M., BOYD, I. L. AND AMOS, W. 2001. LOW reproductive success in territorial male antarctic fur seals (Arctocephalus gazella) suggests the existence of alternative mating strategies. Mol. Ecol., 10, 451-460.

GILligAN, D. M., WOODWORTH, L. M., MONGOMERY, M. E., BRISCOE, D. A. AND FRANKHAM, R. 1997. Is mutation accumulation a threat to the survival of endangered populations? Conserv. Biol., 11, 1235-1241.

GREIG, J. C. 1979. Principles of genetic conservation in relation to wildlife management in Southern Africa. S. Afr. Wildl. Res., 9, $57-78$.

GROOMBRIDGE, J. J., JONES, C. G., BRUFORD, M. W. AND NICHOLS, R. C. 2000. 'Ghost' alleles of the Mauritius kestrel. Nature, 403, 616.

GULlAND, F. M. D., ALBON, S. D., PEMBERTON, J. M., MOORCROFT, P. R. AND CLUTTON-BROCK, T. H. 1993. Parasite-associated polymorphism in a cyclic ungulate population. Proc. R. Soc. B, 254, 7-13.

HAUSER, T. P. AND LOESCHKE, v. 1996. Drought stress and inbreeding depression in Lychnis flos-cucli (Caryophyllaceae). Evolution, 50, $1119-1126$.

HEDRICK, P. W. 1994. Purging inbreeding depression and the probability of extinction: full-sib matings. Heredity, 73, 363-372.

HEDRICK, P. W. 1995. Gene flow and genetic restoration - the Florida panther as a case study. Conserv. Biol., 9, 996-1007.

HEDRICK, P. W., MILLER, P. S., GEFFEN, E. AND WAYNE, R. 1997. Genetic evaluation of three captive Mexican wolf lineages. Zoo. Biol., 16, 47-69.

HEDRICK, P. W. AND KALINOWSKI, S. T. 2000. Inbreeding depression in conservation biology. Ann. Rev. Ecol. Syst., 31, 139-162.

HILTON-TAYLOR (compiler) 2000. 2000 IUCN Red list of Threatened Species. IUCN, Gland, Switzerland and Cambridge, UK.

HOELZEL, A. R., HALLEY, J. AND O'BRIEN, S. J. 1993. Elephant seal genetic variation and the use of simulation models to investigate historical population bottlenecks. J. Hered., 84, 443-449.

HUXEL, G. R. 1999. Rapid displacement of native species by invasive species. Biol. Cons., 89, 143-152.

JAMES, J. W. 1970. The founder effect and response to artificial selection. Genet. Res., 16, 241-250.

JENNIONS, M. D. AND PETRIE, M. 2000. Why do females mate multiply? A review of the genetic benefits. Biol. Rev., 75, 21-64.
JIMENEZ, J. A., HUGHES, K. A., AlAKS, G., GRAHAM, L. AND LACY, R. C. 1994. An experimental study of inbreeding depression in a natural habitat. Science, 266, 271-273.

KALINOWSKI, S. T., HEDRICK, P. W. AND MILLER, P. S. 1999. No inbreeding depression observed in Mexican and red wolf captive breeding program. Conserv. Biol., 13, 1371-1377.

KELLER, L. 1998. Inbreeding and its fitness effects in an insular population of song sparrows (Melospiza melodia). Evolution, 52, 240-250.

KELLER, L. F., ARCESE, P., SMITH, J. N. M., HOCHACHKA, W. M. AND STEARS, S. C. 1994. Selection against inbred song sparrows during a natural population bottleneck. Nature, 372, 356-357.

Kelley, J. L., GRAVes, J. A. AND MAGURRAN, A. E. 1999. Familiarity breeds contempt in guppies. Nature, 401, 661-662.

LACY, R. C. AND LINDENMAYER, D. B. 1995. A simulation study of the impacts of population subdivision on the mountain bushtail possum Trichosurus caninus Ogilby (Phalangeridae, Marsupialia) in southeastern Australia. 2. Loss of genetic variability within and between subpopulations. Biol. Cons., 73, 131-142.

LEVIN, D. A., FRANCISCO-ORTEGA, J. AND JANSEN, R. K. 1996. Hybridization and the extinction of rare plant species. Conserv. Biol., 10, $10-16$.

LYNCH, M. 1993. The mutational meltdown in asexual populations. J. Hered., 84, 339-344.

LYNCH, M. 1996. A quantitative-genetic perspective on conservation issues. In: Avise, J. C. and Hamrick, J. L. (eds) Conservation Genetics. Case Histories from Nature, pp. 471-501. Chapman \& Hall, New York.

MEAGHER, S., PENN, D. J. AND POTTS, W. K. 2000. Male-male competition magnifies inbreeding depression in wild house mice. Proc. Natl. Acad. Sci. U.S.A., 97, 3324-3329.

MEROLA, M. 1994. Reassessment of homozygosity and the case for inbreeding depression in the cheetah, Acinonyx jubatus - implications for conservation. Conserv. Biol., 8, 961-971.

NEWMAN, D. AND PILSON, D. 1997. Increased probability of extinction due to decreased genetic effective population size: Experimental populations of Clarkia pulchella. Evolution, 51, 354-362.

O'BRIEN, S. J. 1994. A role for molecular genetics in biological conservation. Proc. Natl. Acad. Sci. U.S.A., 91, 5748-5755.

O'BRIEN, S. J., ROELKE, M. E., MARKER, L., NEWMAN, A., WINKLER, C. A., MELTZER, D. ET $A L$. 1985. Genetic basis for species vulnerability in the cheetah. Science, 227, 1428-1434.

O'BRIEN, S. J., WILDT, D. E. AND BUSH, M. 1986. The cheetah in genetic peril. Sci. Am., 254, 84-92.

O'BRIEN, S. J., WILDT, D. E., GOLDMAN, D., MERRILl, C. R. AND BUSH, M. 1983. The cheetah is depauperate in genetic variation. Science, 221, 459-462.

PATTEN, M. A. AND CAMPBell, K. F. 2000. Typological thinking and the conservation of subspecies: the case of the San Clemente Island loggerhead shrike. Divers. Distrib., 6, 177-188.

PEMBERTON, J. M., SMith, J. A., COULSON, T. N., MARShall, T. C., SLATE, J., PATERSON, S. ET AL. 1996. The maintenance of genetic polymorphism in small island populations: large mammals in the Hebrides. Phil. Trans. R. Soc. B, 351, 745-752.

RALLS, K., BRUGGER, K. AND BALLOU, J. 1970. Inbreeding and juvenile mortality in small populations of ungulates. Science, 206, 1101-1103.

REED, D. H. AND BRYANT, E. H. 2000. Experimental tests of minimum viable population size. Anim. Cons., 3, 7-14.

RHYMER, J. M. AND SIMBERLOFF, D. 1996. Extinction by hybridisation and introgression. Ann. Rev. Ecol. Syst., 27, 83-109.

SACCHERI, I., KUUSSAARI, M., VIKMAN, P., FORTELIUS, W. AND HANSKI, I. 1998. Inbreeding and extinction in a butterfly metapopulation. Nature, 392, 491-494. 
SACCHERI, I. J., BRAKEFIELD, P. M. AND NICHOLS, R. A. 1996. Severe inbreeding depression and rapid fitness rebound in the butterfly Bicyclus anynana (Satyridae). Evolution, 50, 2000-2013.

SLATE, J., KRUUK, L. E. B., MARShAll, T. C., PEMBERTON, J. M. AND CLUTTON-BROCK, T. H. 2000. Inbreeding depression influences lifetime breeding success in a wild population of red deer (Cervus elaphus). Proc. R. Soc. B, 267, 1657-1662.

TREGENZA, T. AND WEDELL, N. 2000. Genetic compatibility, mate choice and patterns of parentage. Mol. Ecol., 9, 1013-1027.
WEBER, D. S., STEWART, B. S., GARZA, J. C. AND LEHMAN, N. 2000. An empirical genetic assessment of the severity of the northern elephant seal population bottleneck. Curr. Biol., 10, 1287-1290.

WYNEN, L. P., GOLDSWORTHY, S. D., GUINET, C., BESTER, M. N., BOYD, I. L., GJertz, J. G. ET AL. 2000. Postsealing genetic variation and population structure of twospecies of fur seal (Arctocephalus gazella and A. tropicalis). Mol. Ecol., 9, 299-314. 